\title{
TIM Lecture Series: The Business of Mobile Apps Brian Hurley
}

\author{
"I am happy to freely share my knowledge and experiences" \\ to help you in achieving your goals. My only expectation \\ is that you will do the same for others in the future. \\ Brian Hurley \\ President and CEO of Purple Forge
}

\begin{abstract}
The first lecture of the 2012 TIM Lecture Series was presented by Brian Hurley, President and CEO of Purple Forge (http://purpleforge.com/), who generously shared his experiences and insights gained from running a successful mobile applications company. The presentation was targeted at individuals interested in starting their own mobile apps company, particularly those with a background in computer science, engineering, or business. The event was held on February 9, 2012 at Carleton University in Ottawa, Canada.
\end{abstract}

The TIM Lecture Series is hosted by the Technology Innovation Management program (TIM; http://carleton.ca/tim) at Carleton University. The lectures provide a forum to promote the transfer of knowledge from university research to technology company executives and entrepreneurs as well as research and development personnel. Readers are encouraged to share related insights or provide feedback on the presentation or the TIM Lecture Series, including recommendations of future speakers.

This report summarizes the presentation and its key messages, including the lessons learned and actions identified by audience members. The slides from his presentation are available here: http://purplejunction.com/2012/02/09/2322/

\section{Part 1: Building a Mobile App Business}

Mobile Apps can be characterized as the new "gold rush". Brian Hurley began the presentation by sharing "gold rush stories" illustrating that: i) prospectors were lured in the mobile apps space by reports of individual developers reaping significant rewards from seemingly trivial applications, ii) prospectors underestimate the difficulty in coming up with a "good idea" that includes a path to making money, and iii) prospectors need to validate this path to money with prospective customers.

Before developing an idea, an entrepreneur needs to understand that, in the mobile apps space, money can be made in three ways:
1. By selling products (e.g., pay for downloads, advertising, digital goods, subscription),

2. By selling services (e.g., build apps on contract, sell hosted apps to customers)

3. By selling complementary products (e.g., license source code to developers, sell cloud services to developers, sell complementary hardware)

Close consideration should also be given to the key attributes of smartphones and why people use apps. These factors can help generate ideas and highlight opportunities. However, the strongest message in the first part of the presentation was that entrepreneurs should 


\section{TIM Lecture Series: The Business of Mobile Apps}

\section{Brian Hurley}

generate and validate ideas by talking to prospective customers. When combined with a detailed internal evaluation of the idea, external feedback is the surest way to narrow down a list of potential ideas to the ones most likely to be profitable.

In the remainder of this first part of the presentation, Hurley provided insights related to:

1. Defining the target market

2. Building a team with the necessary mix of skills

3. Pulling together the various components of an application

4. Choosing a platform

5. Outsourcing infrastructure

6. Managing the app production cycle

\section{Part 2: Selling, Challenges, Operationalizing}

The second half of the presentation focused on: i) selling mobile apps, ii) overcoming particular challenges, and iii) operationalizing a mobile apps business.

The various strategies for "getting your app noticed" were analyzed using several Purple Forge apps as examples following a detailed discussion of the advantages and disadvantages of each of the four most common sales channels for mobiles apps:

\section{Resellers}

2. Partners

\section{Direct}

\section{App Stores}

The technology challenges faced by mobile apps businesses include: testing, multi-language support, multiversion support, multi-platform support, upgrade management, development environment and skills management, and fragmentation.

The business challenges faced by mobile apps businesses include: app store restrictions and polices, pri- vacy, security, PCI compliance, open source risk management, rapidly changing trends and demographics, provenance/copyright, intellectual property risks, and intellectual property ownership issues.

Next, insights related to operationalizing a mobile apps business were shared. The presentation concluded with advice for funding the business in its early stages and leveraging networks, technologies, and programs to increase the odds of being a winner in the new gold rush.

\section{Lessons Learned}

In the discussions that followed the first and second parts of the presentation, audience members shared the lessons learned they learned from the presentation and injected their own knowledge and experience into the conversation. The presenter and several audience members highlighted the high growth potential for the mobile applications space.

The audience also identified the following key takeaways from the presentation:

1. It is very hard to develop (and validate with customers) an opportunity that will make money for the firm.

2. Validation with customers should be incremental and continuous. You cannot go from the 1st floor to the 10th floor in one step. Continuously validate the goodness of ideas, opportunities, and ventures with customers.

3. Business and development are tied up in a knot; they do not follow a linear sequence that says develop first and sell later. Entrepreneurs should not expect that releasing an application into an app store will be sufficient. An app store is not a business model. Similarly, the idea that "if you build it, they will come" is nonsense. In the mobile applications space in particular, development should proceed only if a strong business model is in place.

4. A business model includes three components: i) value propositions for customers, partners, investors, and employees; ii) resources and processes used to deliver on these value propositions; and iii) a formula to make profits.

5. Intellectual property is important, and so is information. 


\section{TIM Lecture Series: The Business of Mobile Apps}

\section{Brian Hurley}

6 . There is a need to inject a sense of reality into the mobile space. While the mobile apps boom can be thought of as being similar to the gold rush, it is worth remembering that many (most?) prospectors did not make substantial amounts of money during the gold rush.

7. Revenue is all you need, and you must secure customers to generate revenue.

8. The three most important challenges for a startup are: cash, cash, and cash.

A further list of "tips for becoming a successful entrepreneur in the mobile applications space" was developed from the audience reactions to the presentation:

1. Make cold calls and talk to potential customers.

2. Focus on money-making opportunities, not development opportunities.

3. Prioritize deal-making.

4. Set objectives and act to achieve them.

5. Know your market demographics.

6. Make sure you secure channels to market.

7. Encourage media to notice your firm and its products/services.

8. Realize that you cannot make money by developing applications by yourself; to launch and grow a business, you need to work with others.

9. Stick to your core competence and outsource the rest.

10. Put founder agreements in writing; good paper makes good friends.

\section{Suggested Next Steps}

To conclude the evening, the host - Dr. Tony Bailetti, Director of the TIM program - challenged the audience to identify actions that could be taken to improve opportunities for new and existing mobile businesses in Ottawa:

1. Launch Lead to Win Mobile, a suggested variation of the Lead to Win program (http://leadtowin.ca).

2. Set up a culture where firms collaborate to cross-promote their products and services.

3. Organize developers so they can collectively take on larger and more profitable contracts.

4. Establish a job board or speed dating events that enable developers looking for work and firms looking for developers to find each other.

5. Write a paper on business models used by mobile application companies.

\section{About the Speaker}

Brian Hurley is an entrepreneurial leader with over 25 years of experience in building strong teams, innovative products, and international businesses. Brian is currently CEO of Purple Forge which he founded in 2008. He founded Liquid Computing in 2003 and, as its CEO, raised over $\$ 44 \mathrm{M}$ in venture financing, built a world-class team, delivered an award winning product to market, and won initial sales. Brian has built and led numerous successful business teams at Nortel, Bell-Northern Research, and Microtel Pacific Research. Brian is the bestselling author of "A Small Business Guide to Doing Big Business on the Internet". Brian graduated from Carleton University with a Bachelor of Engineering.

Citation: Hurley, B. 2012. TIM Lecture Series: The

Business of Mobile Apps. Technology Innovation Management Review. March 2012: 32-34. (cc) BY 